Association for Information Systems

AIS Electronic Library (AISeL)

\title{
What Goes Around, Comes Around: The Effects of 360- Degree Experiences on Peer-To-Peer Platform Behavior
}

Anke Greif-Winzrieth

Karlsruher Institut für Technologie

Christian Peukert

Karlsruher Institut für Technologie

David Dann

Karlsruher Institut für Technologie

Greif-Winzrieth, Anke; Peukert, Christian; and Dann, David, "What Goes Around, Comes Around: The Effects of 360- Degree Experiences on Peer-To-Peer Platform Behavior" (2021). Wirtschaftsinformatik 2021 Proceedings. 7.

https://aisel.aisnet.org/wi2021/GFuture18/Track18/7

This material is brought to you by the Wirtschaftsinformatik at AIS Electronic Library (AISeL). It has been accepted for inclusion in Wirtschaftsinformatik 2021 Proceedings by an authorized administrator of AIS Electronic Library (AISeL). For more information, please contact elibrary@aisnet.org. 


\title{
What Goes Around, Comes Around: The Effects of 360- Degree Experiences on Peer-To-Peer Platform Behavior
}

\author{
Anke Greif-Winzrieth ${ }^{1}$, Christian Peukert ${ }^{1}$, and David Dann ${ }^{1}$ \\ ${ }^{1}$ Karlsruhe Institute of Technology, Institute of Information Systems and Marketing, \\ Karlsruhe, Germany \\ \{anke.greif-winzrieth, christian.peukert, david.dann\}@kit.edu
}

\begin{abstract}
Platforms for peer-to-peer accommodation sharing are flourishing and changing the overall tourism industry. Ever since, providers on those platforms use photos to advertise their accommodation. Due to the advancement of virtual reality technology, nowadays, it is technologically feasible to provide 360-degree photos with reasonable effort. Yet, popular platforms do not offer the possibility of providing 360-degree photos. To explore what effect an implementation of 360-degree photos could have on consumer behavior, this article sets out to investigate how different presentation formats (ordinary photos, 360-degree desktop, virtual reality) influence consumer perception within a laboratory experiment. Testing these presentation formats in a pilot study $(\mathrm{N}=45)$, we observe significant differences regarding consumers' diagnosticity, enjoyment, and transaction intention, while trust-related variables did not differ substantially. With the outlined research endeavor, we expect to contribute to a better understanding of virtual reality's potential in the platform economy.
\end{abstract}

Keywords: Virtual Reality, Platform Economy, 360-degree Experiences.

\section{Introduction}

The number of bookings on peer-to-peer (P2P) accommodation sharing platforms is ever increasing, so that such platforms have become an integral part of the tourism industry [1]. In contrast to ordinary B2C platforms, on $\mathrm{P} 2 \mathrm{P}$ platforms, users are dealing with private individuals (peers) and, thereby, may face fraudulent offers or inappropriate conditions [2]. To bridge existing information asymmetry between the two peers (i.e., provider and consumer) and enable transactions, trust is a crucial prerequisite [3-6]. To engender trust, providers on P2P accommodation platforms usually substantiate their accommodation's actual quality by presenting (several) photos. Nowadays, it would also be feasible to provide 360-degree content, which allows for conveying a more complete illustration of the offerings (floor plan, layout, size). Similarly in recent years, virtual reality (VR) technology has advanced in a manner that it is now readily available to the broad consumer population (driven by falling prices and at the same time increasing system performance) and can thus be used to approach customers in a novel fashion [7, 8]. However, up to now, such a feature is not yet implemented on any major P2P platform, even though 360-degree photos can

16th International Conference on Wirtschaftsinformatik,

March 2021, Essen, Germany 
be created with virtually all contemporary mobile phones (e.g., using the Google Street View app). Within the tourism industry, several hotel chains and travel agencies (e.g., TUI) are already offering 360-degree experiences to provide customers with comprehensive pre-booking experiences on their potential travel destinations. Further, users' demand for 360-degree photos has already been expressed in forums of major P2P platforms [9]. Against this backdrop, our research endeavor's overarching research question is: How do 360-degree views influence users' perceptions of $P 2 P$ accommodation sharing platform offerings?

Within this research in progress paper, we present results from an exploratory pilot study and propose an experimental design for further investigation of user behavior on P2P accommodation sharing platforms that provide 360-degree content. We compare three treatments where participants either see ordinary photos (Desktop Plain) or $360^{\circ}$ photos presented either on a desktop screen (Desktop 360) or in a VR headset (VR).

\section{Theoretical Background and Related Work}

Since the rise of the platform economy, IS research has investigated various drivers and impediments of the use of P2P accommodation platforms $[5,10]$. Trust is an essential factor that most studies agree on, rendering it a key influencing variable for platform usage [4]. Scholars started to break down trust into different facets, namely trust in the peer (provider or consumer), trust in the platform, and trust in the product (only relevant from a consumer perspective) [4]. Accordingly, platforms are particularly designed to support these trust relations and implement user interface artifacts to establish trust [6]. In this context, it is surprising that the potential of including 360-degree experiences into the design of $\mathrm{P} 2 \mathrm{P}$ platforms has not yet received much attention - neither from a scientific perspective nor from the platform providers themselves.

A growing number of hotels provide 360-degree representations of the rooms on their websites, but there is still little research on how these new presentation formats influence actual booking behavior. In most cases, these 360-degree experiences consist of panoramic photos, that can be accessed via different devices, including smartphones, tablets, desktop computer screens, or VR headsets. The main difference between these devices lies in the degree of immersion that can be delivered. Immersion is systemspecific [11] and has been defined as "the extent to which the computer displays are capable of delivering an inclusive, extensive, surrounding and vivid illusion of reality to the senses of a human participant" [10, pp. 604/605]. VR headsets thus deliver a higher degree of immersion than desktop screens, smartphones, or tablets based on the system specifications.

VR has emerged as a rapidly growing technology, and its implications, fields of usage, and possibilities are continually increasing. A related study by Suh and Lee [13] shows that providing VR access to web stores can increase customer learning about products and purchase intentions. In the tourism context, VR provides several opportunities, such as building an a priori sensory experience of a travel destination [14], which has been shown to increase the likelihood of visiting the destination itself in the future [15]. Overall, existing studies suggest that the presence of VR interfaces 
may enrich customer experiences during the booking process and thus influence booking behavior. Depending on the hardware used and the nature of a 360-degree experience, applications can be classified in different degrees of immersion [12], which, in turn, may affect the telepresence perception [16, 17]. Comparing behavior in 2D and $3 \mathrm{D}$ virtual worlds displayed on a desktop screen, Nah et al. found a significant effect on perceived telepresence and perceived enjoyment [18]. Similarly, Peukert et al. [19] revealed that a VR shopping experience significantly increases the perceived telepresence (and further telepresence positively affects enjoyment) compared to a desktop experience. Evaluating offers on P2P platforms, consumers must rely on the information provided by the supplying peer (e.g., the content transmitted via the presented images). Thereby, the presentation format may substantially influence their perceived diagnosticity. In this context, Jiang and Benbasat [20-22] already showed that different virtual product experiences increase the perceived diagnosticity compared to pallid picture presentation.

\section{$3 \quad$ Pilot Study}
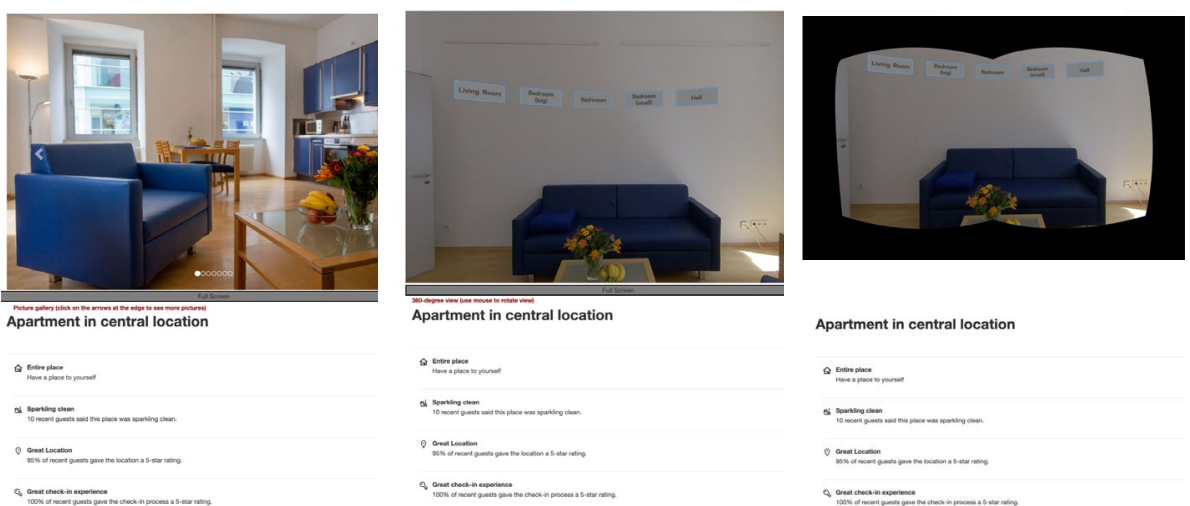

Figure 1. Experimental design for Desktop Plain (left), Desktop 360 (middle), and VR (right) treatment. Exemplary visualization of the representation (top), general information about the accommodation (bottom).

Our pilot study investigates how different presentation formats influence several variables of interest related to user perceptions and behavior on $\mathrm{P} 2 \mathrm{P}$ accommodation sharing platforms (variables printed in bold in Section 2). In the scenario-based lab experiment, participants take on a prospective guest's role on a P2P sharing platform evaluating an accommodation. They were instructed to imagine that they are looking for a place to stay in a foreign town for two nights and use an online platform such as Airbnb, 9flats, or Wimdu. We use a fully-furnished accommodation, presented in three different treatments (tested between subjects): Frist, the Desktop Plain treatment is aligned towards the presentation of accommodations on contemporary $\mathrm{P} 2 \mathrm{P}$ accommodation sharing platforms. Participants can assess the accommodation by browsing several photos (taken by a professional photographer using a Canon EOS $5 \mathrm{~d}$ 
Mark II). Second, the Desktop 360 treatment provides participants with an interactive 360 view of each room (using an Insta360 ONE X placed in the middle of each room). Using drag \& drop mouse gestures, the angle of view can be rotated, and virtual buttons allow to navigate into all other rooms. Third, in the $V R$ treatment, participants are equipped with an Oculus Go head-mounted display and a controller to assess the room in a VR environment. The general information about the accommodation below the treatment is constant across treatments. Figure 1 provides an overview of the three treatments.

Following the treatment, participants were asked to answer a set of survey items. To ensure content validity, we use validated scales adapted to the context of our study (telepresence [18, 23, 24], diagnosticity [25], trust in provider [26], trust in product [4], enjoyment [27, 28], booking intention [29]). We recruited 68 participants from the subject pool of the Karlsruhe Decision and Design Lab (KD $\left.{ }^{2} \mathrm{Lab}\right)$ using hroot [30]. Three observations were excluded because participants failed an attention check, and we lost 20 survey responses due to technical issues ${ }^{1}$. This leads to a sample of 45 participants (mean age 22.9 years, $\mathrm{SD}=3.79 ; 36 \%$ female). The experiment is implemented in oTree [31] and React 360 [32]. All scales meet the commonly applied Cronbach's alpha cutoff value of $>.70$ [33], except trust in product for which one item had to be dropped for further analysis. Significant differences in telepresence perceptions between groups (ANOVA, $F_{(1,43)}=7.97, p=.007$ ) and higher telepresence in VR than in Desktop Plain (Wilcox rank-sum test, $p=.004$ ), but not between VR and Desktop 360 or Desktop Plain and Desktop 360, indicate that our manipulation was partly successful. We evaluate the treatment's effect on the variables of interest with a set of ANOVAs and post-hoc Wilcox rank-sum tests and find significant differences between treatments for diagnosticity, enjoyment, and intention to book (Figure 1). We find no significant differences between treatments in trust-related variables.
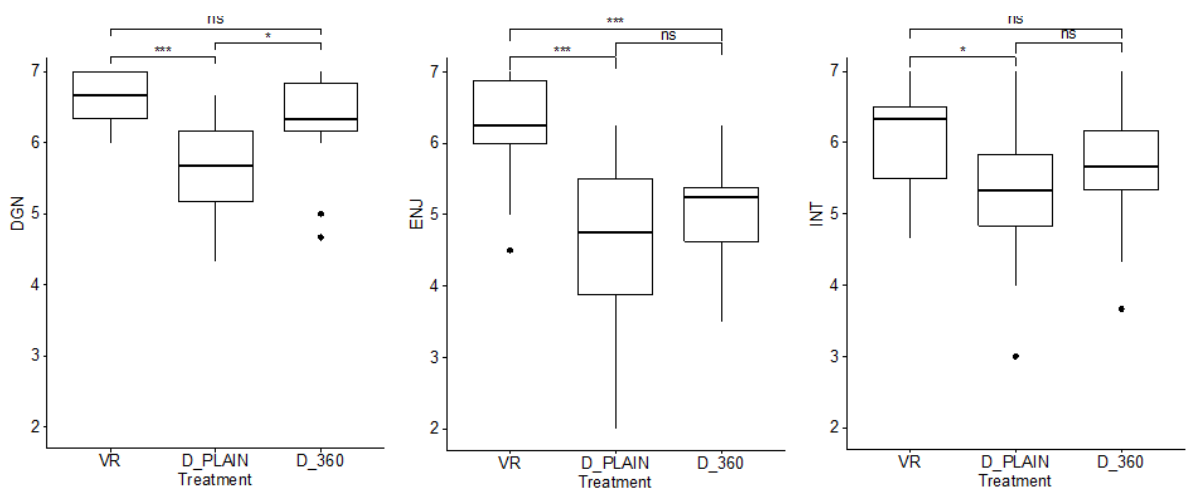

Figure 2. ANOVA analysis for diagnosticity $\left.F_{(1,43)}=6.55, p=.014\right)$, enjoyment $\left(F_{(1,43)}=22.2\right.$, $p<.001)$, and intention to book $\left(F_{(1,43)}=3.72, p=.06\right) . * *:<.001, * *:<.01, *:<.05$.

${ }^{1}$ Due to a coding mistake, some items were not displayed to the participants, such that the data for some constructs was incomplete. This was fixed after the first session, ensuring data quality for the remaining sessions considered for analysis. 


\section{Expected Contribution and Future Work}

Beyond important learnings for our main study, the results of the pilot study already provide valuable insights. First, we find significant differences between the perceptions of telepresence and diagnosticity among the VR and the Desktop Plain treatment groups. Nevertheless, the results of comparing these groups to the Desktop 360 group remain inconclusive. This indicates that VR and Desktop Plain may constitute two extrema with the Desktop 360 treatment somewhere in between. For the main study, we may consider reducing the set of treatments by omitting the Desktop 360 treatment in the first place. If we find support for the pilot study results suggesting that the effects of Desktop Plain and VR differ significantly, we could further investigate the spectrum between these two extrema by including the Desktop 360 treatment and further treatments like the presentation of 360-degree photos on mobile devices that allow for more interactive navigation (e.g., moving the device to change the perspective).

For the main study, we further expect valuable insights from the analysis of behavioral variables, including the time spent in each room or the areas of visual attention. We also consider enhancing the VR treatment by enabling participants to "walk" through the virtual representation (similar to Google Street View). Another interesting topic is to challenge our results' external validity by validating if the effects remain stable when replacing the Insta360 ONE X photos with 360-degree photos generated with common mobile phone applications. To further substantiate the main study's external validity, the overall experimental design follows a two-staged procedure. First, a booking-phase, in which participants inform themselves about an accommodation in a laboratory environment, and second, a visit-phase, in which participants visit the respective accommodation in the real world. From a theoretical perspective, the Expectation Confirmation Theory [34] may represent a suitable lens for our study's theoretical embedding.

We expect our main study's contribution to be twofold. First, to the best of our knowledge, our study represents the first to assess the effect of 360-degree experience on P2P platform behavior. Thereby, the study may demonstrate that 360-degree photos constitute a new kind of trust-building signal that has not yet received much attention in literature. Furthermore, uncovering mediators between different representation formats and transaction intentions may provide valuable theoretical insights for scholars and platform designers. Second, our results have implications for platform operators and users. Platform operators can use the results to evaluate whether the integration of 360-degree experiences makes sense for their platform and how it affects their users' behavior. Evaluating key economic indicators such as the booking intention shows if more profits can be generated through 360-degree experiences or if it is just a marketing gimmick. On the other hand, platform users can benefit on the providing side (i.e., the host) by leveraging 360-degree photos to acquire more transactions and, eventually, demand higher prices. On the consuming side (i.e., the guests), they may benefit by being able to evaluate offers in a more detailed manner, thereby having a better feeling when entering the transaction and ultimately seeing their expectations more fulfilled when arriving at the accommodation. 


\section{References}

1. Dann, D., Teubner, T., Weinhardt, C.: Poster child and guinea pig-Insights from a structured literature review on Airbnb. Int. J. Contemp. Hosp. Manag. 31, (2019). https://doi.org/10.1108/IJCHM-03-2018-0186.

2. AirbnbHell: AirbnbHell: uncensored Airbnb stories from hosts and guests, https://www.airbnbhell.com/, last accessed 2019/02/15.

3. Gebbia, J.: How Airbnb Designs for Trust, (2016).

4. Hawlitschek, F., Teubner, T., Weinhardt, C.: Trust in the Sharing Economy. Die Unternehmung - Swiss J. Bus. Res. Pract. 70, 26-44 (2016). https://doi.org/10.5771/0042-059X-2016-1-26.

5. Möhlmann, M., Geissinger, A.: Trust in the sharing economy: Platform-mediated peer trust. In: Handbook on the Law of the Sharing Economy. Cambridge University Press (2018).

6. Hesse, M., Dann, D., Braesemann, F., Teubner, T.: Understanding the platform economy: Signals, trust, and social interaction. In: HICSS 2020 Proceedings. pp. 1-10 (2020).

7. Yang, S., Xiong, G.: Try It On! Contingency Effects of Virtual Fitting Rooms. J. Manag. Inf. Syst. 36, 789-822 (2019). https://doi.org/10.1080/07421222.2019.1628894.

8. Flavián, C., Ibáñez-Sánchez, S., Orús, C.: The impact of virtual, augmented and mixed reality technologies on the customer experience. J. Bus. Res. 100, 547-560 (2019). https://doi.org/10.1016/j.jbusres.2018.10.050.

9. Airbnb Community Center: How can I add a 360 Virtual Tour to my listing?, https://community.withairbnb.com/t5/Hosting/How-can-I-add-a-360-Virtual-Tour-tomy-listing/td-p/30741/page/7, last accessed 2019/08/09.

10. Hawlitschek, F., Teubner, T., Gimpel, H.: Understanding the Sharing Economy Drivers and Impediments for Participation in Peer-to-Peer Rental. In: Proceedings of the 49th Hawaii International Conference on System Sciences. pp. 4782-4791 (2016). https://doi.org/10.1109/HICSS.2016.593.

11. Bowman, D.A., McMahan, R.P.: Virtual reality: How much immersion is enough? Computer (Long. Beach. Calif). 40, 36-43 (2007). https://doi.org/10.1109/MC.2007.257.

12. Slater, M., Wilbur, S.: A framework for immersive virtual environments (FIVE): speculations on the role of presence in virtual environments. Presence Teleoperators Virtual Environ. 6, 603-616 (1997).

13. Suh, Lee: The Effects of Virtual Reality on Consumer Learning: An Empirical Investigation. MIS Q. 29, 673 (2005). https://doi.org/10.2307/25148705.

14. Guttentag, D.A.: Virtual reality: Applications and implications for tourism. Tour. Manag. 31, 637-651 (2010). https://doi.org/10.1016/j.tourman.2009.07.003.

15. Gibson, A., O'Rawe, M.: Virtual Reality as a Travel Promotional Tool: Insights from a Consumer Travel Fair. 93-107 (2018). https://doi.org/10.1007/978-3-319-64027-3_7.

16. Schultze, U., Orlikowski, W.J.: Research commentary-Virtual worlds: A performative perspective on globally distributed, immersive work. Inf. Syst. Res. 21, 810-821 (2010). https://doi.org/10.1287/isre.1100.0321.

17. Sharda, R., Romano, N.C., Lucca, J.A., Weiser, M., Scheets, G., Chung, J.M., Sleezer, 
C.M.: Foundation for the study of computer-supported collaborative learning requiring immersive presence. J. Manag. Inf. Syst. 20, 31-64 (2004). https://doi.org/10.1080/07421222.2004.11045780.

18. Nah, F.F.-H., Eschenbrenner, B., DeWester, D.: Enhancing brand equity through flow and telepresence: a comparison of 2D and 3D virtual worlds. MIS Q. 35, 731-747 (2011).

19. Peukert, C., Pfeiffer, J., Meißner, M., Pfeiffer, T., Weinhardt, C.: Shopping in Virtual Reality Stores: The Influence of Immersion on System Adoption. J. Manag. Inf. Syst. 36, 755-788 (2019). https://doi.org/10.1080/07421222.2019.1628889.

20. Jiang, Z., Benbasat, I.: Virtual Product Experience: Effects of Visual and Functional Control of Products on Perceived Diagnosticity and Flow in Electronic Shopping. J. Manag. Inf. Syst. 21, 111-147 (2005).

21. Jiang, Z., Benbasat, I.: The effects of presentation formats and task complexity on online consumers' product understanding. MIS Q. 31, 475-500 (2007).

22. Jiang, Z., Benbasat, I.: Investigating the influence of the functional mechanisms of online product presentations. Inf. Syst. Res. 18, 454-470 (2007). https://doi.org/10.1287/isre.1070.0124.

23. Kim, T., Biocca, F.: Telepresence via television: two dimensions of telepresence may have different connections to memory and persuasion. J. Comput. Commun. 3, (1997).

24. Klein, L.R.: Creating virtual product experiences: the role of telepresence. J. Interact. Mark. 17, 41-55 (2003).

25. Xu, J.D., Benbasat, I., Cenfetelli, R.T.: The nature and consequences of trade-off transparency in the context of recommendation agents. MIS Q. 38, 379-406 (2014).

26. Gefen, D., Karahanna, E., Straub, D.W.: Inexperience and experience with online stores: The importance of TAM and trust. IEEE Trans. Eng. Manag. 50, 307-321 (2003). https://doi.org/10.1109/TEM.2003.817277.

27. Koufaris, M.: Applying the technology acceptance model and flow theory to online consumer behavior. Inf. Syst. Res. 13, 205-223 (2002).

28. Ghani, J.A., Supnick, R., Rooney, P.: The experience of flow in computer-mediated and in face-to-face groups. In: Proceedings of the International Conference on Information Systems. pp. 229-237 (1991).

29. Gefen, D., Straub, D.W.: Managing User Trust in B2C e-Services. e-Service J. 2, 7-24 (2003).

30. Bock, O., Baetge, I., Nicklisch, A.: hroot: Hamburg Registration and Organization Online Tool. Eur. Econ. Rev. 71, 117-120 (2014). https://doi.org/10.1016/j.euroecorev.2014.07.003.

31. Chen, D.L., Schonger, M., Wickens, C.: oTree-An open-source platform for laboratory, online, and field experiments. J. Behav. Exp. Financ. 9, 88-97 (2016). https://doi.org/10.1016/j.jbef.2015.12.001.

32. Facebook Inc.: React 360.

33. Bagozzi, R.P., Yi, Y.: On the evaluation of structural equation models. J. Acad. Mark. Sci. 16, 74-94 (1988).

34. Oliver, R.L.: A Cognitive Model of the Antecedents and Consequences of Satisfaction Decisions. J. Mark. Res. 17, 460-469 (1980). https://doi.org/10.1177/002224378001700405. 